\title{
Cardiorespiratory Endurance and Obesity Based on Socioeconomic Status of Family Among School Children
}

Nurul Diyana Sanuddin, Nur Atikah Mohamed Kassim, Rozella Ab Razak, Adjullea anak James @ Noew, Asmalini Che Abu Shafie, Theresa Ahing

To Link this Article: http://dx.doi.org/10.6007/IJARBSS/v11-i11/11528～DOI:10.6007/IJARBSS/v11-i11/11528

Received: 03 September 2021, Revised: 27 September 2021, Accepted: 19 October 2021

Published Online: 07 November 2021

In-Text Citation: (Sanuddin et al., 2021)

To Cite this Article: Sanuddin, N. D., Kassim, N. A. M., Razak, R. A., Noew, A. anak J. @, Shafie, A. C. A., \& Ahing, T. (2021). Cardiorespiratory Endurance and Obesity Based on Socioeconomic Status of Family Among School Children. International Journal of Academic Research in Business and Social Sciences, 11(11), 191 197.

\section{Copyright: (c) 2021 The Author(s)}

Published by Human Resource Management Academic Research Society (www.hrmars.com)

This article is published under the Creative Commons Attribution (CC BY 4.0) license. Anyone may reproduce, distribute, translate and create derivative works of this article (for both commercial and non-commercial purposes), subject to full attribution to the original publication and authors. The full terms of this license may be seen at: http://creativecommons.org/licences/by/4.0/legalcode

Vol. 11, No. 11, 2021, Pg. 191 - 197 


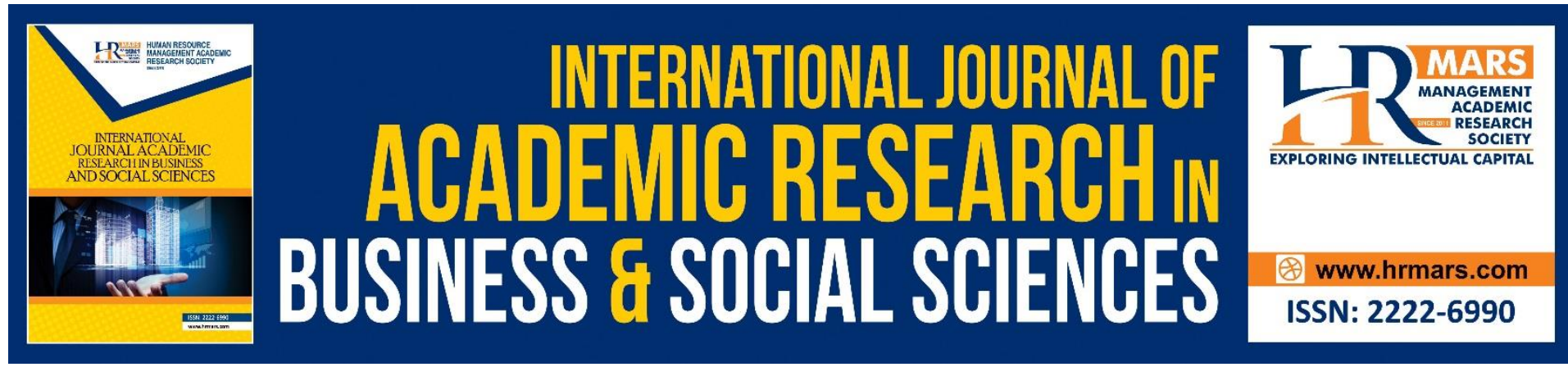

\title{
Cardiorespiratory Endurance and Obesity Based on Socioeconomic Status of Family Among School Children
}

\author{
Nurul Diyana Sanuddin ${ }^{1}$, Nur Atikah Mohamed Kassim¹, \\ Rozella Ab Razak ${ }^{1}$, Adjullea anak James @ Noew ${ }^{2}$, Asmalini \\ Che Abu Shafie ${ }^{2}$, Theresa Ahing ${ }^{2}$ \\ ${ }^{1}$ Faculty of Sport Science \& Recreation, Universiti Teknologi MARA UiTM Cawangan Pahang, \\ Kampus Jengka, Malaysia, ${ }^{2}$ Faculty of Sport Science \& Recreation, Universiti Teknologi \\ MARA UiTM Cawangan Sarawak, Kampus Kota Samarahan, Malaysia \\ Email: diyanasanuddin@uitm.edu.my
}

\begin{abstract}
Research was conducted to identify the influence of socioeconomic status and life style among children in Perak related to health-related fitness. Selected schools among children in Perak trying to prove children lifestyle have a great influence to their body composition and researcher tend to measured how much energy expenditure that the children attain they expend when performs any type of physical activity especially when do cardiorespiratory training. A total of 120 students from selected primary schools in Perak were involved in this research and they represented three main races in Malaysia. Participant need to complete the 1600 meters run or walk (cardiorespiratory endurance), measuring height, weight and skinfold thickness (body composition and fat percentage) and answering questionnaire. The finding of this study showed, there were significance different between cardiorespiratory endurance and socioeconomic status of the children was 0.044 less than alpha value 0.05 $(F=3.210 ; p=0.044<0.05)$. Besides that, the significant value of physical activity, leisure time and activity at school were $(F=0.855 ; p=0.428>0.05),(F=2.789 ; p=0.066>0.05)$, and $(F=11.036 ; p=0.000<0.05)$. Moreover, for body composition and fat percentage, was no significant differences between socioeconomic statuses of family in body mass index $(F=1.580 ; p=0.210>0.05)$, and skinfold thickness of male $(F=1.910 ; p=0.156>0.05)$, and female $(F=0.558 ; p=0.576>0.05)$. As conclusion, children need to know about the important of physical activity included education about increasing lifestyle related to physical activity such as aerobic, walking to schools and other.
\end{abstract}

Keywords: Cardiorespiratory Endurance, Obesity, Socioeconomic Status, Children

\section{Introduction}

It was reported that 5.3 millions of death per year worldwide caused by physical inactivity. Half a millions of death could be avoided every year if this physical inactivity reduced by only $10 \%$ (Pratt et al., 2015). Low level of physical activity among youngsters was not only 
encountered by a country but significantly low globally. This situation continues to be a major public health problem in neither developed and developing countries (Zhu et al., 2019).

Extremely time spent and chronically engaged in gadgets such as computer games and watching television were among factors that leads to lack of involvement in physical activities as well as commitment to school homework and enjoying family wealth and status. These contributed to the increasing rate of obesity among children (Lau et al., 2019). Leh, and his friends (2020), discovered that their interest was more towards social health such as personal appearance compared to healthy lifestyle which focus on physiological and physical needs of health. On the other hand, the socioeconomic status of the family also affected children's physical activities involvement to become sedentary, as well as affecting their healthy diet. Living in a low socioeconomic status can affect negatively the health of children which usually related to quality nutrition intake, medical care and opportunity to engage in physical activities (Zhu et al., 2019).

Obesity was a serious medical concern in children and teenagers as well as in adults. Overweight or obesity has become a big health issue all over the globe and Malaysia was no exception. According to the World Health Organization (WHO), in the year of 2016, $18 \%$ of children and adolescents in the range age of 5-19 years old were found overweight or obese. Among Asian countries, Malaysia came in the first rank with $64 \%$ of males and $65 \%$ of females who were overweight or obese. It was also reported statistically by WHO that Malaysian children age ranged $9-16$ years old was $12.7 \%$ with obesity (WHO, Overweight and obesity, 2016). With the statistic report shown and more to come which will contribute to this study, childhood obesity will remain as the main topic to be explore in this study.

Changes in lifestyle due to living in urban settings may also affect physical fitness. Environmental and social changes related to living in urban areas such as crowding, fast food restaurants, changing neighbourhood, safety worries and inadequate grounds for play may possibly contribute to lower levels of physical fitness among indigenous children and adolescents. Popovska et al (2020), found that there was a significance of living area as a determinant of physical fitness in children and adolescents. Therefore, children's health related fitness across geographic boundaries has suggested to be studied.

The evaluation of childhood obesity is crucial in order to minimize the progression of the disease and its subsequent morbidity to adulthood. Regular diet and exercise routines in children and awareness of unnecessary weight gain due to normal development are important during childhood. This will encourage children themselves from being obese and provide a way to avoid any causes that may exacerbate childhood obesity (Katzmarzyk et al., 2015).

Rapid development process cause by socioeconomic development in Malaysia has impacted the demographic profile of the population. The rate of being physically active and obesity issue could be affected by the family socioeconomic status. Changes in the lifestyle and diet in urban and rural areas was affected by rapid socioeconomic development. 


\section{Research Method \\ Research Design}

The researcher has used two methods in gathering the data which were experimental and qualitative approaches. Experimental research has been conducted in order to gain the needed information. Based on the information obtained, the researcher will describe the data collected. A set of questionnaire also has been employed in order to obtain related information to the study. Data collection was done by the involvement of both children and family members or parents. In determining the level of physical activity on the cardiorespiratory endurance and its relation to body composition value, the subjects were asked to perform two tests; the 1600-meter run and the body composition measurement. Meanwhile, their family or parents were asked to complete a set of questionnaire given. A child's physical fitness was assessed with two activities includes the aerobic capacity (cardiorespiratory endurance) and body composition (BMI) as well as skin-fold thickness. Children were divided into the following categories; upper class, middle class and lower class of family based on their socioeconomic status.

\section{Measuring Instrument}

Body Composition Measurement

Body mass $(\mathrm{kg})$, stature $(\mathrm{m})$, and the skinfold thickness with measure the sum of triceps, iliac, abdominal for female and sum of calf, chest, and abdominal for male. The percentage of body fat of the subject was gender specifically calculated based on Jackson-Pollock standard for body fatness. The BMI of each subject was calculated using the formula for BMI. A BMI of less than $18.5 \mathrm{~kg} / \mathrm{m}^{2}$ indicated underweight, more than $25 \mathrm{~kg} / \mathrm{m}^{2}$ and $30 \mathrm{~kg} / \mathrm{m}^{2}$ indicates overweight and obesity.

Physical Measurement

Children will be divided into three categories which consist of upper class of family, middle class of family and lower class of family. A common method to measure aerobic cardiovascular endurance/ cardiorespiratory endurance, which endurance run/ walking test (1600m).

\section{Procedure}

Approval to conduct this study was permission from head master of every schools and consent was given by parents. The response rate was $100 \%$ from the participants, head master and their parents.

\section{Discussion of Results}

Based on the data collected and processed, result showed the value of significance different between children socioeconomic status on cardiorespiratory endurance was 0.044 less than alpha value $0.05(F=3.210 ; p=0.044<0.05)$. This study found that the lower socioeconomic status of family had the greater access and enhance on cardiorespiratory endurance compare with the higher socioeconomic status of family. 
Table 1: Analysis of variance (ANOVA) for physical activity, leisure time and activity at school

\begin{tabular}{llllll}
\hline Item & Lower Class & Middle Class & Upper Class & F & sig \\
\cline { 2 - 4 } & Mean & Mean & Mean & & \\
\hline $\begin{array}{l}\text { Cardiorespiratory } \\
\text { Endurance }\end{array}$ & 4.73 & 4.93 & 5.53 & $\mathbf{3 . 2 1 0}$ & $\mathbf{0 . 0 4 4}$ \\
\hline
\end{tabular}

Based on the table 2 was showed, that the value of significance different between children socioeconomic status of family on physical activity, leisure time and activity at school. From the result had reported, the significance value for physical activity was 0.428 which greater than alpha value 0.05 ( $F=0.855 ; p=0.428>0.05)$. The significance value for leisure time was 0.066 which greater than alpha value $0.05(F=2.789 ; p=0.066>0.05)$. Finally, for variable activity at school, the significance value was 0.000 which less than alpha value 0.05 ( $F=11.036$; $p=0.000<0.05)$, even though, there no significance difference of physical activity and leisure time between group, but the mean between group was higher.

Table 2: Analysis of variance (ANOVA) for physical activity, leisure time and activity at school

\begin{tabular}{llllll}
\hline \multirow{2}{*}{ Item } & Lower Class & Middle Class & Upper Class & \multirow{F}{*}{} & \multirow{2}{*}{ sig } \\
\cline { 2 - 4 } & Mean & Mean & Mean & & \\
\hline Physical Activity & 24.98 & 21.34 & 20.76 & $\mathbf{0 . 8 5 5}$ & $\mathbf{0 . 4 2 8}$ \\
\hline Leisure Time & 193.25 & 134.80 & 179.47 & $\mathbf{2 . 7 8 9}$ & $\mathbf{0 . 0 6 6}$ \\
\hline Activity at School & 33.08 & 23.92 & 23.58 & $\mathbf{1 1 . 0 3 6}$ & $\mathbf{0 . 0 0 0}$ \\
\hline
\end{tabular}

Referring to table 3 , it showed that the value of significance different between children socioeconomic status of family on body mass index (BMI), and skinfold thickness. From the result had reported, the significance value between group for body mass index (BMI) of the test was 0.210 which was greater than alpha value 0.05 ( $F=1.580 ; p=0.210>0.05)$ and the significance value between groups for skinfold thickness on male was 0.156 which greater than alpha value $0.05(F=1.910 ; p=0.156>0.05)$, and skin fold thickness on female was 0.576 which also greater than alpha value 0.05 ( $F=0.558 ; p=0.576>0.05)$. Thus, there was no significant difference between socioeconomic statuses of family on skinfold thickness. However, body mass index (BMI) and skinfold thickness show the higher prevalence of normal compare of overweight subjects. Difference between body mass index (BMI) and skinfold thickness based on socioeconomic status of family might be due to a high level of physical activity and the high population of lower body mass relative to their height.

Table 3: Analysis of variance (ANOVA) for obesity

\begin{tabular}{llllll}
\hline Item & Lower Class & Middle Class & Upper Class & F & \multirow{2}{*}{ sig } \\
\cline { 2 - 4 } & Mean & Mean & Mean & & \\
\hline Body Mass Index & 1.53 & 1.73 & 1.45 & $\mathbf{1 . 5 8 0}$ & $\mathbf{0 . 2 1 0}$ \\
\hline Skinfold Thickness & & & & & \\
\hline Male & 2.47 & 3.04 & 3.44 & $\mathbf{1 . 9 1 0}$ & $\mathbf{0 . 1 5 6}$ \\
\hline Female & 2.33 & 2.06 & 2.62 & $\mathbf{0 . 5 5 8}$ & $\mathbf{0 . 5 7 6}$ \\
\hline
\end{tabular}

\section{Findings \& Discussion}

There are three objectives in this study includes to determine differences between socioeconomics status in level of cardiorespiratory endurance among children nine to eleven year's 
old at several districts in Perak. Most of subjects are underweight category and they are committed to any physical activities. The result is different because some of them are not consistent in performing their cardiorespiratory endurance and they do not achieve the level of cardiorespiratory endurance which 80-90 percent of the maximum heart rate. Yet research has conclusively demonstrated the effectiveness of exercises training in promoting major alterations in body composition and improvement in several cardiorespiratory endurance and maintaining fitness includes exercise that address cardiorespiratory endurance optimal body composition, muscular strength and endurance and flexibility. This study to determine whether there were any differences between children who come from high-and low-income family with is spent more time with physical activity or leisure time. The analysis showed that there was significant difference between socioeconomic statuses of family in physical activity and leisure time. This because, children from lower class of family more interested on physical activity compared to the leisure time and it have shown that students from upper class more engaged on leisure time such play computer games (Fang et al., 2019).

\section{Conclusion}

As a conclusion, socioeconomic status does have a great impact in cardiorespiratory status of a child. The findings in this study has shown that a significant different on cardiorespiratory endurance based on socioeconomic status of family existed. The ability of the heart, lungs and muscles to work in a longer period of time increased by improving aerobic endurance. A combination of a good nutrition and actively engaging in physical activity could help in promoting lifelong health benefits and disease prevention. Encouragements from the whole family was important in ensuring children actively involved in physical activities. Encouragements and supports could be differ based on their socioeconomic backgrounds. The Children Physical Activity Questionnaire that been used in the data collection might includes of total time that the children spend on physical activity, leisure time activities and activity at school compare on socioeconomic status of family that indicated to the various activity. This study found that children from lower class more interested in physical activity compared to the leisure time. Meanwhile, children from upper class of socioeconomic status family were more likely to engage in leisure time activities such as playing computer games compare to involve in physical activity such as play basketball, volleyball and others. Children need to be educate and need to know on the importance of physical activity as well as about increasing lifestyle related to activity such as aerobic, walking to schools and others. Children should not too focus on the sedentary activities especially on playing computer games, watching television and others related activities while outside the school. Therefore, children should be encourage to be engaged in enjoyable, developmentally appropriate physical activity for one to two hours daily. Finally, it can be conclude that there was a high influence of socioeconomic status and its environment towards the body mass index (BMI) and skinfold thickness in all children. It has been decades and documented in many previous studies that body fat content was a serious issue. Increasing in participation in physical activities as well as sporting culture was the only curative measure to address the matter (An et al., 2019).

\section{Acknowledgement}

The researchers would like to express their deep appreciation to students, teachers and schools involved in the data gathering for their help and generous support. 


\section{References}

An, R., Shen, J., Yang, Q., \& Yang, Y. (2019). Impact of built environment on physical activity and obesity among children and adolescents in China: a narrative systematic review. Journal of sport and health science, 8(2), 153-169.

Fang, K., Mu, M., Liu, K., \& He, Y. (2019). Screen time and childhood overweight/obesity: A systematic review and meta-analysis. Child: care, health and development, 45(5), 744753.

Katzmarzyk, P. T., Barreira, T. V., Broyles, S. T., Champagne, C. M., Chaput, J. P., Fogelholm, M. (2015). Relationship between lifestyle behaviors and obesity in children ages 9-11: results from a 12-country study. Obesity. 2015;23(8):1696-702.

Lau, X. C., Wong, Y. L., Wong, J. E., Koh, D., Sedek, R., Jamil, A. T., ... \& Poh, B. K. (2019). Development and Validation of a Physical Activity Educational Module for Overweight and Obese Adolescents: CERGAS Programme. International journal of environmental research and public health, 16(9), 1506.

Leh, O. L. H., Musthafa, S. N. A. M., Solahuddin, M., Hamzah, M. A. M., \& Mabahwi, N. A. (2020). Health and Physical Activity in Urban Neighbourhoods. Case Study: Shah Alam City, Selangor, Malaysia. Built Environment, 17(2), 11-20.

Popovska, K., Gontareva, N., Kalac, R., \& Todorovski, S. (2020). Differences Between Physical Fitness Profiles of Children in Urban and Suburban Area in The Municipality of Kisela Voda. Research in Physical Education, Sport \& Health, 9(1).

Pratt, M., Ramirez, A., Martins, R., Bauman, A., Heath, G., Kohl III, H., ... \& Hallal, P. (2015). 127 steps toward a more active world. Journal of Physical Activity and Health, 12(9), 1193-1194.

Wang, Z., Zhao, L., Huang, Q., Hong, A., Yu, C., Xiao, Q., ... \& Jia, P. (2021). Traffic-related environmental factors and childhood obesity: a systematic review and meta-analysis. Obesity reviews, 22, e12995.

Williams, A. S., Ge, B., Petroski, G., Kruse, R. L., McElroy, J. A., \& Koopman, R. J. (2018). Socioeconomic status and other factors associated with childhood obesity. The Journal of the American Board of Family Medicine, 31(4), 514-521.

Zhu, Z., Tang, Y., Zhuang, J., Liu, Y., Wu, X., Cai, Y., ... \& Chen, P. (2019). Physical activity, screen viewing time, and overweight/obesity among Chinese children and adolescents: An update from the 2017 physical activity and fitness in China-The youth study. BMC public health, 19(1), 197. Worley, G. H. (2011). Wilderness communications. Wilderness Environ Med, 22(3), 262-269. doi:10.1016/j.wem.2011.05.001 